\title{
A comparative study of microbial community and dynamics of Asaia in the brown planthopper from susceptible and resistant rice varieties
}

\author{
Abhishek Ojha ${ }^{1,2}$ and Wenqing Zhang ${ }^{1 *}$ (D)
}

\begin{abstract}
Background: The brown planthopper (BPH) is likely the most destructive, piercing and sucking monophagous insect pest of rice that causes substantial economic losses to farmers. Although yeast-like symbionts (YLS) and virus transmission have been observed in the $\mathrm{BPH}$, the bacterial population inhabiting the $\mathrm{BPH}$ has received minimal research attention. Labelling BPH-associated bacterial species may shed light on BPH biology and the interaction between the BPH and rice to provide novel approaches for the efficient control of this insect pest.

Results: We examined RNA-seq results to identify bacterial populations present in different generations of BPHs maintained on susceptible or resistant rice varieties. Overall, 87 operational taxonomic units (OTUs) were determined from the BPH-F0, F6 and F16 generations. These OTUs had Shannon and Simpson index values of 0.37-0.6 and $0.56-1.19$, respectively. The evenness values of $0.7-1.00$ showed the vastness of the bacterial diversity recovered from the BPH samples. The results showed high species diversity in the BPHs collected from susceptible rice and a high number of members of unclassified bacteria in the BPHs isolated from resistant rice. We noticed that Proteobacteria OTUs were predominant across all samples. Furthermore, PCR data of Asaia species showed variable DNA amplification across the BPH samples collected from susceptible or resistant varieties. The identification of Asaia in BPH eggs and $\mathrm{BPH}$-egg-infected rice revealed its influence on the interaction between the BPH egg and rice.

Conclusions: The BPHs had clear differences in their microbiomes and in their ability to feed on different rice hosts. These variations could have an essential impact on host adaptation and interaction. These results provide a better understanding of the bacterial diversity and interaction of the microbiome of different generations of BPHs. Furthermore, PCR data of Asaia sp. variation across the BPH samples (isolated from different host genotypes selected from the field and laboratory, including BPH eggs and egg-infected rice tissues), suggest that Asaia could be an important member of the insect microbiome involved in adaptation, its interaction with rice and, most importantly, as a paratransgenic tool for insect control.
\end{abstract}

Keywords: Operational taxonomic units, Diversity, Microbiome, $16 \mathrm{~S}$ rRNA, Macropterous and brachypterous $\mathrm{BPH}$, Insect-plant interaction

\footnotetext{
* Correspondence: Isszwq@mail.sysu.edu.cn

${ }^{1}$ State Key Laboratory of Biocontrol and School of Life Sciences, Sun Yat-sen

University, Guangzhou 510275, Guangdong, China

Full list of author information is available at the end of the article
}

(c) The Author(s). 2019 Open Access This article is distributed under the terms of the Creative Commons Attribution 4.0 International License (http://creativecommons.org/licenses/by/4.0/), which permits unrestricted use, distribution, and reproduction in any medium, provided you give appropriate credit to the original author(s) and the source, provide a link to the Creative Commons license, and indicate if changes were made. The Creative Commons Public Domain Dedication waiver (http://creativecommons.org/publicdomain/zero/1.0/) applies to the data made available in this article, unless otherwise stated. 


\section{Background}

Microbes and insects have co-evolved for several hundred million years, and these associations are often reflected by extensive symbiotic relationships between partners. Microbes have been found to be involved in various phenomena of their host insects [1-4]. Previous reports have suggested that two planthopper species, Laodelphax striatellus and Sogatella furcifera, harbour microbes that can be transferred horizontally between different species of insects and strongly influence their hosts' immune response, sexual reproduction and cytoplasmic incompatibility [4-6]. The role of microbes in insects using various molecular techniques has unveiled the unexplored world of microbe-insect interactions. However, further investigations are required to derive fruitful conclusions.

The brown planthopper, BPH, Nilaparvata lugens (Stål) (Hemiptera: Delphacidae) is a major monophagous agricultural pest of rice crops in the temperate and tropical regions of Asia [7]. The BPH has two winged forms (macropterous and brachypterous) at the adult stage. The macropterous (long-winged) $\mathrm{BPH}$ has long-distance migration behaviour [8] and infests rice fields, while the brachypterous (short-winged) $\mathrm{BPH}$ is known for laying many eggs and producing numerous offspring in rice hosts $[9,10]$ and can also quickly overcome resistance genes of its rice host by developing new virulence factors [11-13]. These characteristics make the $\mathrm{BPH}$ difficult to forecast and control. The $\mathrm{BPH}$ infests rice at all stages of plant growth. As a result of feeding by both nymphs and adults at the base of tillers, plants become yellow and ultimately die. This symptom of crop damage is known as "hopper burn" "(http://www.rkmp.co.in/content/brown-plant-hopper-bph)".

Furthermore, recent reports revealed that endosymbionts of insects [14], which show an important role in uric acid metabolism [15], might also play a major role in insect-plant interactions $[16,17]$, thereby forming an integral part of BPH adaption to its rice host. However, while $\mathrm{BPH}$-associated microbiomes and their modes of action are known, their stability is not clear. Here, we examine and classify the bacterial population of the $\mathrm{BPH}$ in an attempt to explain this interaction and gain important insights into this interaction to develop a new approach to manage this serious insect pest.

\section{Results}

\section{Taxonomic diversity index}

The taxonomic diversity (normal distribution and alphaand beta-diversity) of the bacterial population was analysed using RNA-seq data from different generations of adult female BPH samples. Normal distributions of the bacterial population within the $\mathrm{BPH}$ samples were calculated using the Shapiro-Wilk W and Anderson-Darling A test (see Additional file 1). The Shapiro-Wilk W index of normality ranged from 0.6 to 0.820 , with a $P$-value of 0.0002 to 0.064 . The observed Anderson-Darling A probability distribution ranged from 0.565 to 1.423 , with a $P$-value of 0.0003 to 0.088 (see Additional file 1). Alpha-diversity indices (Shannon, Simpson, Evenness, Brillouin, Fisher alpha, BergerParker and Chao1) of the bacterial population were notably distinct within the BPH samples (Table 1). Shannon diversity values varied from 0.37 to 0.64 , Simpson diversity values varied from 0.56 to 1.19 , Evenness diversity values varied from 0.70 to 1.00 and Brillouin information diversity values varied from 0.34 to 0.99 (Table 1). The Fisher alpha and Berger-Parker species richness values ranged from 0.00 to 2.38 and 0.40 to 0.75 , respectively (Table 1 ). The species richness (Chao1) estimator indicated that species richness ranged from 2 to 4, with the highest value in BPH-F16TN1 and BPH-F16-IR36 among the BPH samples (Table 1) . Notably, the BPH-F16-TN1 sample had more operational taxonomic units (OTUs) than the other BPH samples (Table 1). PAST (Palaeontological Statistics, version 3) software was used to analyse the beta diversity of the bacterial population between the BPH samples (as shown by PCoA). PCoA (principal coordinate analysis; similarity and distance) was calculated using eigenvalues and eigenvectors (coordinates). The similarity/distance eigenvalues were raised to the power of $C$ (the transformation exponent) before Eigen analysis, and the standard value was $C=2$. The "Eigenvalue scaling" option scale was used for each axis using the square root of the eigenvalue, and the minimal spanning tree option was based on the selected similarity or distance index. Similarity- and distance-PCoA estimated the presence or absence of bacterial species between the BPH (BPH-F0, BPH-F6-TN1, BHP-F16-TN1, BPH-F6IR36, BPH-F16-IR36, BPH-F6-RH, and BPH-F16-RH) samples (Fig. 1). Similarity- (Fig. 1a) and distance-PCoA (Fig. 1b) plots revealed the bacterial diversity in the samples and noticeably separated the $\mathrm{BPH}-\mathrm{FO}, \mathrm{BPH}-$ F6-TN1, BHP-F16-TN1, BPH-F6-IR36, BPH-F16-IR36, BPH-F6-RH, and BPH-F16-RH samples. Evaluation of the PCoA data of pair-wise $\mathrm{BPH}$ sample comparisons was performed using Bonferroni correction (Table 2). Eight pair-wise $\mathrm{BPH}$ sample comparisons (BPH-F0 and BPH-F6-TN1, BPH-F0 and BPH-F6-IR36, BPHF6-TN1 and BPH-F6-IR36, BPH-F6-TN1 and BPHF6-RH, BPH-F16-TN1 and BPH-F6-IR36, BPH-F6-IR 36 and BPH-F16-IR36, BPH-F6-IR36 and BPH-F6-RH, and BPH-F6-IR36 and BPH-F16-RH) had a Bonferroni corrected $P$-value of 1.0 , and the remaining 34 pairwise sample comparisons had Bonferroni corrected $P$ values in the range of 0.987 to 0.00 (Table 2). Furthermore, the Whittaker indices for similarities between bacterial communities of the $\mathrm{BPH}$ samples ranged from 0.143-0.666 (Table 3). 
Table 1 Alpha-diversity indices and the estimated richness of the bacterial population in the BPH samples

\begin{tabular}{llllllllll}
\hline S. No. & Sample name & Shannon & Simpson & Evenness & Brillouin & Fisher_alpha & Berger-Parker & Chao1 & Observed Species \\
\hline 1. & BPH-F0 & 0.46 & 0.80 & 0.74 & 0.58 & 1.45 & 0.70 & 3 & 10 \\
2. & BPH-F6-TN1 & 0.64 & 1.05 & 0.95 & 0.80 & 1.45 & 0.40 & 3 & 10 \\
3. & BPH-F16-TN1 & 0.56 & 1.03 & 0.70 & 0.86 & 1.34 & 0.60 & 4 & 25 \\
4. & BPH-F6-IR36 & 0.50 & 0.69 & 1.00 & 0.34 & 0.00 & 0.50 & 3 & 2 \\
5. & BPH-F16-IR36 & 0.64 & 1.19 & 0.82 & 0.99 & 1.43 & 0.50 & 4 & 22 \\
6. & BPH-F6-RH & 0.50 & 0.86 & 0.79 & 0.56 & 2.38 & 0.66 & 4 & 6 \\
7 & BPH-F16-RH & 0.37 & 0.56 & 0.87 & 0.44 & 0.68 & 0.75 & 2 & 12 \\
& Total & 3.67 & 6.18 & 5.87 & 4.57 & 8.73 & 4.11 & 23 & 87 \\
\hline
\end{tabular}

The bacterial diversity (Shannon, Simpson index, Evenness and Brillouin) and OTUs richness (Fisher_alpha, Berger-Parker and Chao1) were estimated at 97\% sequence similarity from each BPH sample. The female adult BPH (BPH-F6-TN1 and BPH-F16-IR36) samples revealed highest alpha-diversity among the BPH samples. BPH-F0, F0 generation female adult BPH; BPH-F6-TN1, F6 generation female adult BPH isolated from susceptible, TN1, host; BHP-F16-TN1, F16 generation female adult BPH isolated from TN1; BPH-F6-IR36, F6 generation female adult BPH isolated from resistant, IR36, host; BPH-F16-IR36, F16 generation female adult $\mathrm{BPH}$ isolated from IR36; $\mathrm{BPH}-\mathrm{F} 6-\mathrm{RH}$, F6 generation female adult $\mathrm{BPH}$ isolated from resistant, $\mathrm{RH}$, host; and $\mathrm{BPH}-\mathrm{F} 16-\mathrm{RH}, \mathrm{F} 16 \mathrm{generation}$ female adult $\mathrm{BPH}$ from $\mathrm{RH}$

\section{Distribution of operational taxonomic units (OTUs) and relative abundance analysis}

The identified diverse bacterial species in the BPH samples were classified at different taxonomic levels, phyla, classes, orders, families, and genera (see Additional file 2) . The diversity of OTUs at the phylum level across all BPH samples was determined as follows: Proteobacteria,
Actinobacteria, Bacteroidetes, Firmicutes, Fusobacteria, Euryarchaeota, p_Unclassified, p_ Unclassified and p_ Unclassified (see Additional file 2). Gene Cluster 3.0 and TreeView software was used to generate a heat map representation of the OTUs, and the results evidently revealed the bacterial diversity and the relative abundance of OTUs in the bacterial composition (phylum level)

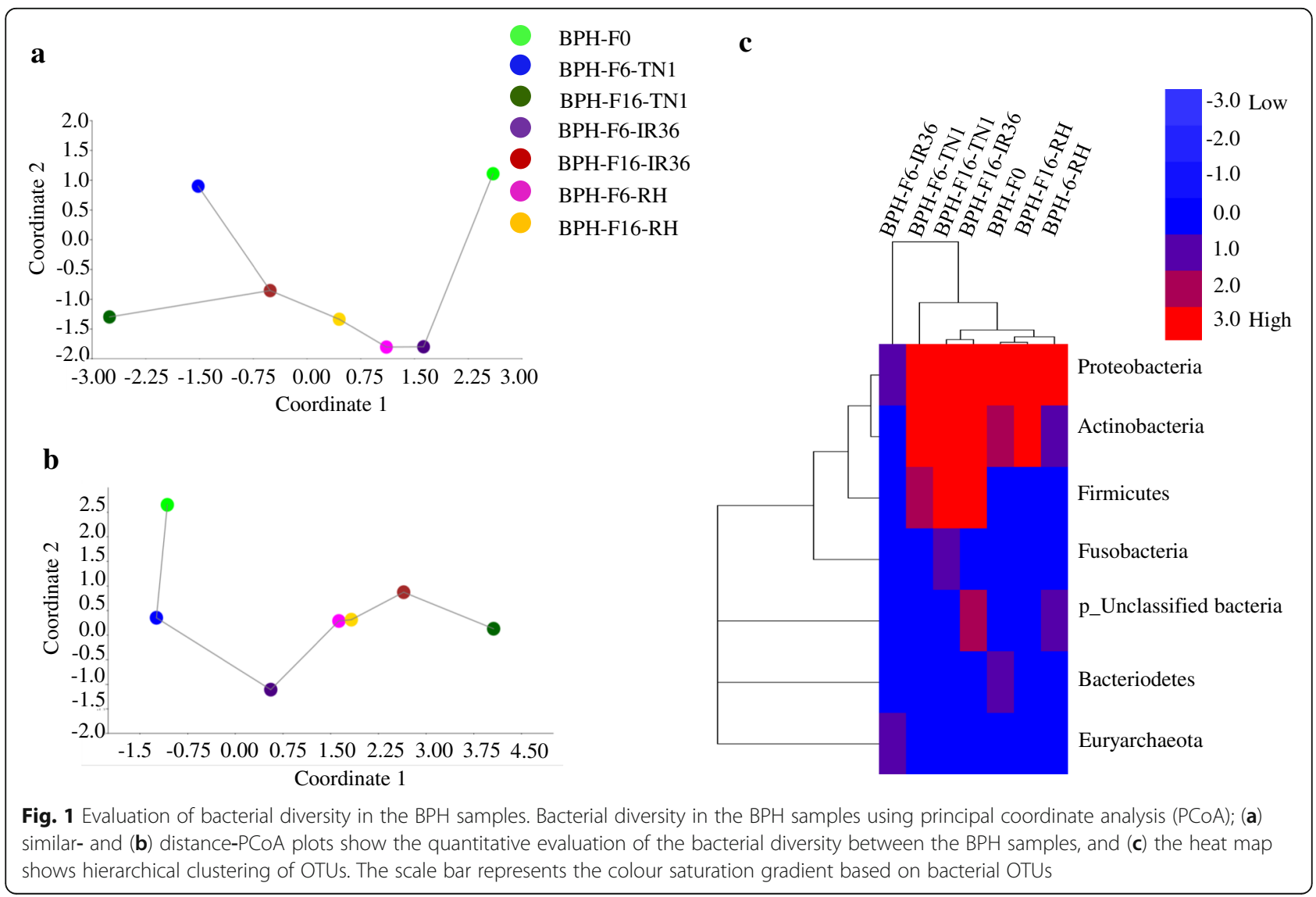


Table 2 Principal coordinate analysis (PCOA)-based pair-wise comparison of bacterial diversity. Eighty-seven bacterial OTUs sequences of the BPH samples were used to calculate the Bonferroni corrected $P$-value

\begin{tabular}{llllllll}
\hline & BPH-F0 & BPH-F6-TN1 & BPH-F16-TN1 & BPH-F6-IR36 & BPH-F16-IR36 & BPH-F6-RH & BPH-F16-RH \\
\hline BPH-F0 & & 1 & 0.015 & 1 & 0.094 & 0.023 & 0.000 \\
BPH-F6-TN1 & 0.739 & & 0.254 & 1 & 0.094 & 0.687 & 0.005 \\
BPH-F16-TN1 & 0.956 & 0.864 & & 1 & 1 & 0.065 & 1 \\
BPH-F6-IR36 & 0.550 & 0.205 & 0.487 & & & 0.002 \\
BPH-F16-IR36 & 0.909 & 0.909 & 0.970 & 0.392 & 0.920 & 0.069 & 0.024 \\
BPH-F6-RH & 0.948 & 0.683 & 0.922 & 0.533 & 0.947 & 0.961 \\
BPH-F16-RH & 0.987 & 0.794 & 0.980 & 0.559 & & \\
\hline
\end{tabular}

among the BPH samples (BPH-F0, BPH-F6-TN1, BPHF16-TN1, BPH-F6-IR36, BPH-F16-IR36, BPH-F6-RH, and BPH-F16-RH) (Fig. 1c).

With a total of 51 bacterial OTUs, Proteobacteria was observed as the predominant phylum among the $\mathrm{BPH}$ samples. Proteobacteria alone shared 7, 4, 15, 1, 11,4 and 9 of the total OTUs in the samples BPHF0, BPH-F6-TN1, BPH-F16-TN1, BPH-F6-IR36, BPHF16-IR36, BPH-F6-RH and BPH-F16-RH, respectively (Fig. 2a). However, bacterial OTUs identified as Actinobacteria were the second dominant phylum, and Actinobacteria shared 22 OTUs of the total OTUs classified. The remaining $8,1,1,1$ and 3 of the total OTUs represented the phylum Firmicutes, Bacteroidetes, Fusobacteria, Euryarchaeota and p_Unclassified, respectively (Fig. 2a, see Additional file 3). The predominant bacterial OTUs, belonging to Proteobacteria among the $\mathrm{BPH}$ samples (Fig. 2b), represented the genera Acinetobacter (10 OTUs); Corynebacterium (8 OTUs); Asaia and Cutibacterium (6 OTUs each); Staphylococcus and Brevundimonas (5 OTUs each); Moraxella (4 OTUs); Micrococcus, Sphingomonas and Escherichia (3 OTUs each); and Ralstonia, Massilia and Occidentia (2 OTUs each); Fusobacterium, Rhizobium, Erwinia, Serratia, Leucobacter, Actinomyces, Fluviicola, Rhodococcus, Alkalibacterium, Anoxybacillus, Delftia, Hydrogenophilus, Bartonella, Chryseobacterium, Cuniculiplasma, Propionibacterium, Lactob acillus, Rhizobacter, Neokamagataea, Thiobacillus,
Rhodovastum, Vitreoscilla, and Uncultured Enhydrobacter (1 OTUs each).

Comparative analysis and identification of bacterial populations between BPH samples collected from susceptible and resistant rice varieties

To study the comparative abundance of the bacterial species across the $\mathrm{BPH}$ samples, we organized the different $\mathrm{BPH}$ (F6 and F16 generations) samples, isolated from susceptible (TN1) and resistant (IR36 and $\mathrm{RH}$ ) rice varieties, into three groups: BPH-(F6 + F16)-TN1, BPH-(F6 + F16)-IR36 and $\mathrm{BPH}-(\mathrm{F} 6+\mathrm{F} 16)-\mathrm{RH}$ samples (Fig. 2c, see Additional file 4). We observed that the number of bacterial species was higher in the BPH-(F6+F16)-TN1 sample and that the number of bacterial species was lower in the BPH-(F6 + F16)-RH sample (Fig. 2c). A total of 36, 20 and 18 bacterial species were detected in the BPH-(F6 + F16)-TN1, BPH$(\mathrm{F} 6+\mathrm{F} 16)-\mathrm{IR} 36$ and BPH-(F6 + F16)-RH samples, respectively (see Additional file 4). Comparing the bacterial populations of the BPH-(F6+F16)-TN1 sample with the BPH(F6 + F16)-IR36 sample, Micrococcus, Staphylococcus, Moraxella, Chryseobacterium, Cutibacterium, Sphingomonas, Asaia, Thiobacillus, Rhodovastum, Fusobacterium, Occidentia, Bartonella, Rhodococcus, Alkalibacterium, and Anoxybacillus were lower in the BPH-(F6 + F16)-IR36 sample (Fig. $2 \mathrm{~b}$, see Additional file 4), while upon comparison of the bacterial populations in the BPH-(F6 + F16)-TN1 sample with the BPH-(F6 + F16)-RH sample, the bacterial population of Micrococcus, Staphylococcus, Corynebacterium, Moraxella,

Table 3 Beta-diversity, Whittaker indices, and pair-wise comparisons between the BPH samples based on bacterial OTUs

\begin{tabular}{llllllll}
\hline Sample name & BPH-F0 & BPH-F6-TN1 & BPH-F16-TN1 & BPH-F6-IR36 & BPH-F16-IR36 & BPH-F6-RH & BPH-F16-RH \\
\hline BPH-F0 & 0 & 0.333 & 0.430 & 0.600 & 0.430 & 0.333 & 0.200 \\
BPH-F6-TN1 & 0.333 & 0 & 0.143 & 0.600 & 0.143 & 0.333 & 0.200 \\
BPH-F16-TN1 & 0.430 & 0.143 & 0 & 0.666 & 0.250 & 0.430 & 0.333 \\
BPH-F6-IR36 & 0.600 & 0.600 & 0.600 & 0 & 0.666 & 0.600 & 0.500 \\
BPH-F16-IR36 & 0.430 & 0.143 & 0.250 & 0.666 & 0 & 0.143 & 0.333 \\
BPH-F6-RH & 0.333 & 0.333 & 0.430 & 0.600 & 0.143 & 0 & 0.200 \\
BPH-F16-RH & 0.200 & 0.200 & 0.333 & 0.500 & 0.333 & 0.200 & 0 \\
\hline
\end{tabular}




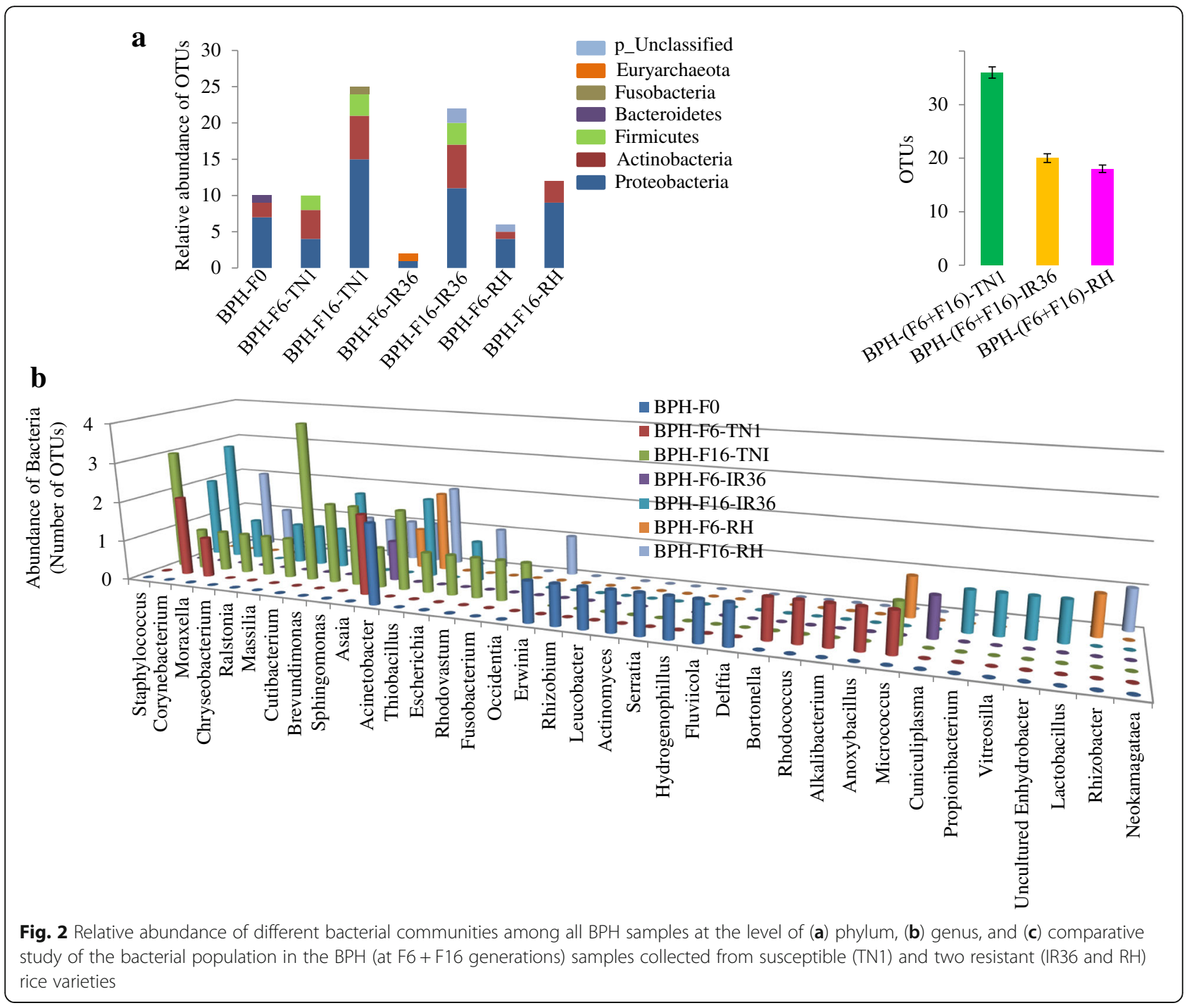

Chryseobacterium, Ralstonia, Massilia, Cutibacterium, Brevundimonas, Sphingomonas, Asaia, Thiobacillus, Rhodovastum, Fusobacterium, Occidentia, Bartonella, Rhodococcus, Alkalibacterium, and Anoxybacillus were lower in the BPH(F6 + F16)-RH sample (Fig. 2b, see Additional file 4). In contrast, Cuniculiplasma, Propionibacterium, Vitreoscilla, uncultured Enhydrobacter, and Lactobacillus were found to be higher in number in the BPH-(F6 + F16)-IR36 sample, while Acinetobacter, Rhizobacter, and Neokamagataea were found to be higher in the BPH-(F6 + F16)-RH sample (Fig. 2b, see Additional file 4). These decreases or increases in the number of bacterial species may affect the survival rates of BPHs on resistant (IR36 and RH) rice varieties compared with the susceptible (TN1) rice varieties.

\section{Specific and shared bacterial population}

The number of specific and shared OTU sequences present in the BPH samples were analysed using a Venn diagram (TBtools (v0.6653) and http://bioinformatics.psb.ugent.be/
cgi-bin/liste/Venn/calculate_venn.htpl) (Fig. 3, see Additional file 5). Thirty-nine specific and 14 shared OTU sequences were identified across all samples. Acinetobacter and Asaia species were shared between five BPH samples, while Staphylococcus, Ralstonia, Massilia, Sphingomonas, Occidentia and uncultured bacteria were shared between only two BPH samples. The remaining 25 bacterial species were specific for each $\mathrm{BPH}$ sample (Fig. 3, see Additional file 5).

Dynamic variability in the occurrence of Asaia in different $\mathrm{BPH}$ samples collected from susceptible and resistant rice varieties

The RNA-seq results revealed that Asaia was the most common bacterial genus between the BPH samples isolated from different rice varieties. Asaia have all of the necessary ecological characteristics (discussed in the discussion section), which indicate its potential to be a member of the paratransgenic tool against the $\mathrm{BPH}$. To 


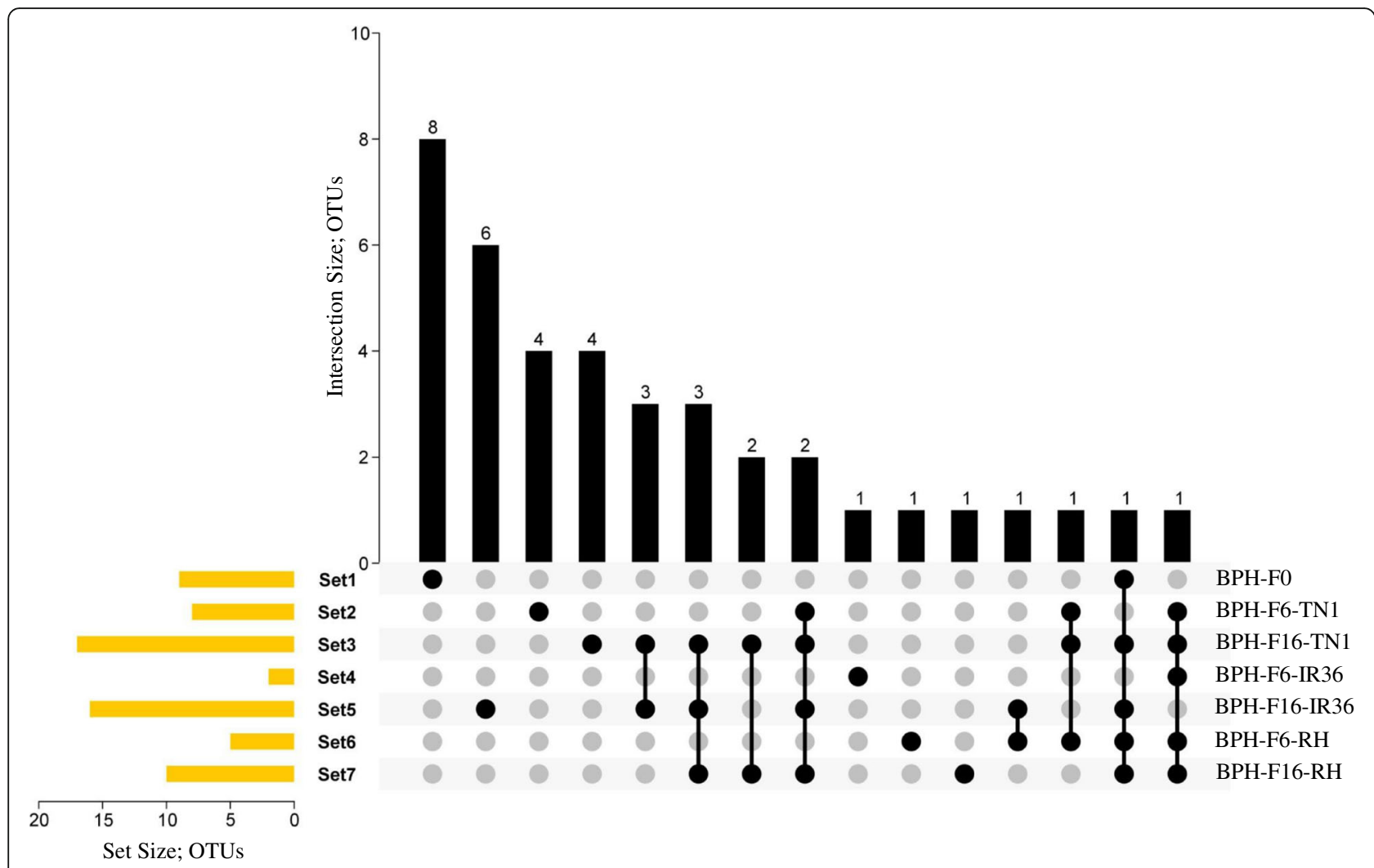

Fig. 3 Identification of specific and shared bacterial populations among the BPH samples

study the presence of Asaia in the different BPH samples, the Asaia-specific 16S rRNA gene was amplified by PCR using an Asaia-specific primer (Fig. 4a-h). Amplification of the Asaia-specific 16S rRNA gene (400 bp) was detected in the long-winged adult (male and female) $\mathrm{BPH}$ (LWBM-HHZ and LWBF-HHZ) samples collected from the "HHZ" susceptible rice variety. However, we noticed a weak PCR signal for Asaia in the field-collected longwinged adult BPH (Field-LWBM and Field-LWBF) samples (Fig. 4a, b). Furthermore, amplification of the Asaiaspecific $16 \mathrm{~S}$ rRNA gene $(400 \mathrm{bp})$ was observed in the long-winged male BPH (LWBM-IR36) sample, but a weak PCR signal for Asaia was observed in the long-winged female BPH (LWBF-IR36) sample collected from the resistant rice IR36 (Fig. 4c, d). Conversely, amplification of the Asaia-specific 16S rRNA gene (400 bp) was detected in the short-winged adult (male and female) BPH (SWBMHHZ and SWBF-HHZ) samples from the "HHZ" susceptible rice (Fig. 4e-h), while we noticed a weak PCR signal for Asaia in the field-collected short-winged adult (male and female) BPH (Field-SWBM and Field-SWBF) samples (Fig. 4e, f). Furthermore, amplification of the Asaia-specific $16 \mathrm{~S}$ rRNA gene $(400 \mathrm{bp})$ was observed in the $\mathrm{BPH}$ (SWBM-IR36 and SWBF-IR36) samples (Fig. 4g, h). Each amplified PCR product, Asaia-specific 16S rRNA gene (400 bp), of the BPH samples was commercially sequenced using the Asaia-specific primers (discussed in the Methods section) at www.igebiotech.com, Guangzhou, China, and the obtained sequencing data were reconfirmed as Asaia sp. using the NCBI-BLAST 16S rRNA database (data not shown). Nevertheless, there is a need to study the significant role of Asaia within their insect host.

\section{Identification of Asaia in the BPH eggs and BPH-egg- infected rice}

To recognize the possible role of Asaia in the interaction between the $\mathrm{BPH}$ and its rice host, we carried out PCR amplification of the Asaia-specific 16S rRNA gene (400 bp) from $\mathrm{BPH}$-egg, $\mathrm{BPH}$-egg-infected and uninfected rice tissue (HHZ susceptible rice) samples. Amplification of the Asaia-specific gene ( $400 \mathrm{bp}$ ) was detected in the BPH eggs and BPH-egg infected rice samples, but there was no amplification of the Asaia-specific gene in the uninfected rice samples (Fig. 4i, j). These PCR products, Asaia-specific $16 \mathrm{~S}$ rRNA gene ( $400 \mathrm{bp})$, were sequenced using the Asaia-specific primers (discussed in the methods section) at www. igebiotech.com, Guangzhou, China, and Sanger sequencing generated sequence data that reconfirmed the sequences as belonging to Asaia sp. using the NCBI-BLAST 16S rRNA database (data not shown). The detection of the PCR signal of the Asaia-specific gene in BPH-egg-infected rice but not in uninfected rice revealed that this bacterium might have 


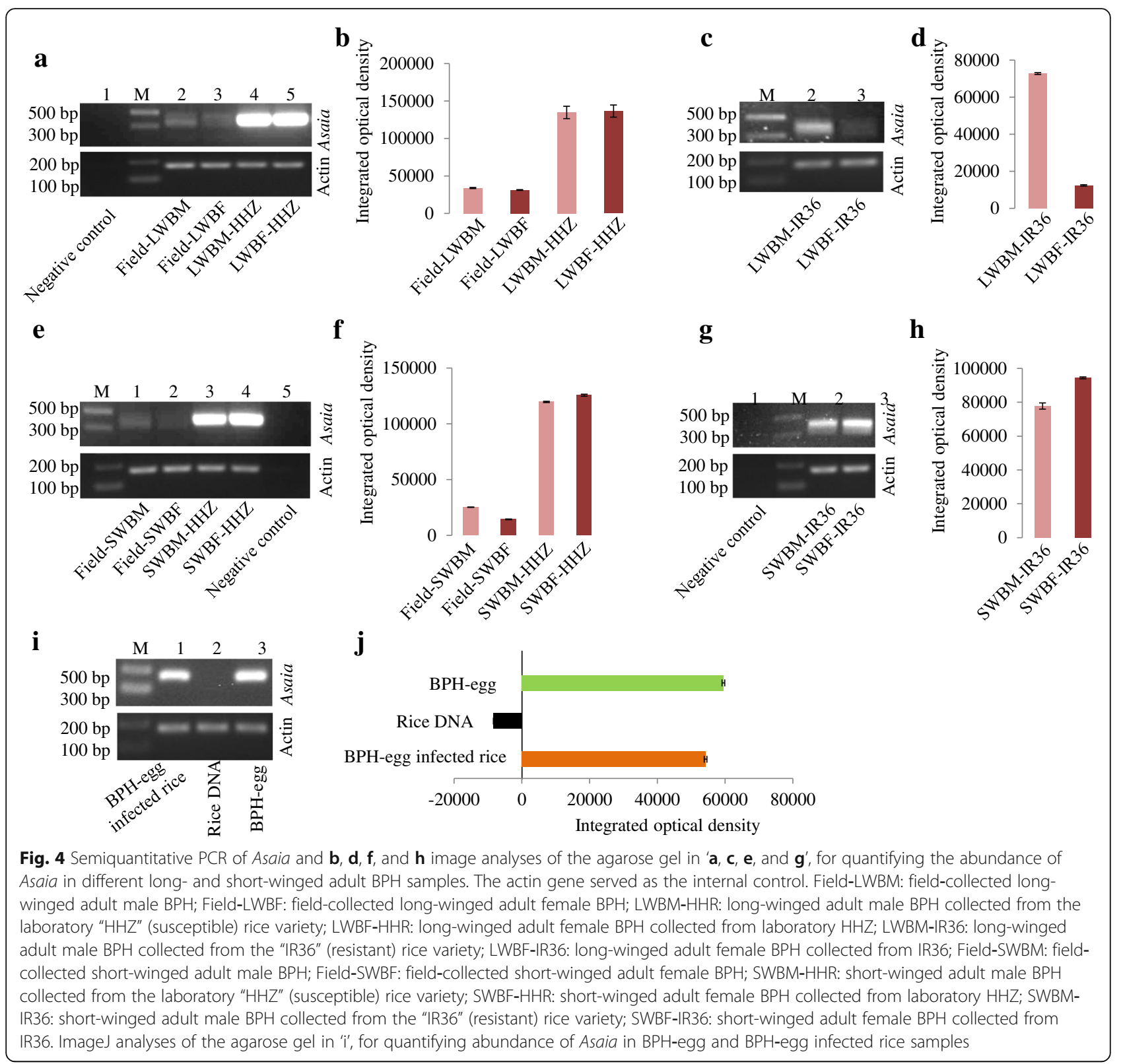

an important role in the interaction between the BPH eggs and the host plant upon which they are laid. However, this requires further verification.

\section{Discussion}

The insect-associated bacterial community is one of the key determinants of insect physiology, but there is limited research on the functionality of the $\mathrm{BPH}$ bacterial community during the interaction between $\mathrm{BPH}$ and rice. The small size of $\mathrm{BPH}$ eggs and poor artificial food make research on the BPH difficult [18]. Therefore, this investigation was carried out to identify the bacterial population and to determine its influential role in the interaction between the BPH and rice [19-22]. Further, it would be worth studying whether BPHs feeding on susceptible and resistant rice genotypes can affect survival due to an increase or decrease in the number of favourable bacteria within them.

This project described various bacterial communities in seven different samples of BPHs. Proteobacteria OTUs were the predominant constituents in all BPH samples, possibly because the feeding stage of the $\mathrm{BPH}$ on rice possessed Proteobacteria, which could then be relocated from the eggs to adults [23]. Furthermore, the BPH samples, depicting only the feeding stage, revealed distinct alphadiversity (Table 2). The previous investigation characterized Proteobacteria as the major bacterial community structure in the habitat [24] due to their effective colonization [25, 
26]. The Proteobacteria community has also been revealed as the major constituent in the Asian rice gall midge, a monophagous dipteran insect [19], Drosophila, a polyphagous [27] dipteran insect and blood feeder bugs i.e., Cimex lectularius [28], Aedes sp. [29] and ticks [30].

The bacterial microbiomes in the BPHs contained both unique and abundant OTUs. These unique species, which were unique to a respective sample, may be indicative of their important role in $\mathrm{BPH}$ physiology and may influence their cooperation with the rice plant. The survival rates of nymphs (BPH) have been reported to be significantly lower on resistant rice hosts than on susceptible rice hosts $[31,32]$. Compared to the bacterial community noted in the BPH-(F6 + F16)-TN1 sample, the BPH-(F6 + F16)IR36 and BPH-(F6 + F16)-RH samples from the resistant rice (IR36 and RH) hosts revealed a lower bacterial population from the genera Micrococcus, Staphylococcus, Corynebacterium, Moraxella, Chryseobacterium, Ralstonia, Massilia, Cutibacterium, Brevundimonas, Sphingomonas, Asaia, Thiobacillus, Rhodovastum, Fusobacterium, Occidentia, Bartonella, Rhodococcus, Alkalibacterium, and Anoxybacillus (see Additional file 4), although there was an enhanced bacterial population from the genera Cuniculiplasma, Propionibacterium, Vitreoscilla, uncultured Enhydrobacter, Lactobacillus, Acinetobacter, Rhizobacter, and Neokamagataea (see Additional file 4). This decrease in various bacterial species in the BPH-(F6 + F16)-IR36 and $\mathrm{BPH}-(\mathrm{F} 6+\mathrm{F} 16)-\mathrm{RH}$ samples may be the cause for BPH-(F6 + F16)-IR36 and BPH-(F6 + F16)-RH mortality because host invariability and demise are equated to change in the native bacterial population, as hypothesized by researchers [33].

Acinetobacter, Corynebacterium and Asaia are opportunistic bacteria that cause infections in humans [34-36]. These 3 bacterial species were identified in all BPH samples. The ten observed Acinetobacter in the samples had maximum sequence identity to $A$. vivianii, $A$. radioresistens, A. halotolerans, A. soli, A johnsonii and A. calcoaceticus (see Additional file 2). Furthermore, it has been reported that plasmids are key elements in prokaryotic evolution and their adaptation to variable environmental circumstances [37]. The existence and broad diversity of plasmids in Acinetobacter are well known for natural transformation [38], metabolic activities or metal resistance [39-41] in their host. However, in the context of $\mathrm{BPH}$, there is still no report regarding whether a similar function of Acinetobacter plasmids within the BPH shows any impact on insight into the BPH-microbe interaction. This is yet to be proven.

Insect cells cannot secrete all kinds of enzymes and thus require microbes to supply specific enzymes for nutrient metabolism [42]. A recent study observed that enzymes are secreted by microbes into their insect host to balance the insect life cycle [43]. In our study, Corynebacterium and Staphylococcus were present among the $\mathrm{BPH}$ samples, and we speculate that these microbes may be involved in manipulating the biological functions of their insect host $[42,44,45]$. Nevertheless, this is yet to be elucidated.

The presence of Asaia sp. in agricultural pests such as Nilaparvata lugens [46], Scaphoideus titanus [47], and Pieris rapae [48] has previously been demonstrated. A previous study reported that Asaia was observed only in front of the ovipositor sheath in the biotype 2 (Mudgo, carrying the resistant gene (Bph1) female BPH [46]. In our study, all RNA-sequencing data showed that Asaia was present in all BPH (excluding BHP-F0 and BPHF16-IR36) samples isolated from susceptible (TN1) and resistant (IR36 and RH) rice varieties, and further PCR signals reconfirmed the presence of Asaia sp. in all BPH samples collected from field, susceptible (Huang Hua Zhan) and resistant (IR36), rice varieties. In the case of Gluconacetobacter [46], Asaia may contribute to metabolic functions that influence the adaptation of the $\mathrm{BPH}$ to both susceptible and resistant rice varieties. However, more information is required to confirm this hypothesis.

Furthermore, Asaia have also been reported in multiple symbioses with the mosquito. They influence the interaction with both Plasmodium and Anopheles [49], possess strong adhesive properties [50], act as an immune-modulator activating antimicrobial peptide expression [49], accelerate larval development [51, 52], are transmitted from mother to offspring likely by a mechanism of egg smearing [53], are capable of crosscolonizing insects of phylogenetically distant genera and order [54], are proposed as a tool for the control of mosquito-borne diseases, specifically malaria $[55,56]$, and have positive markers for functional nitrogenise activity [57]. Therefore, a similar role is likely to be possible in the $\mathrm{BPH}$ as well. In our study, Asaia was observed in $\mathrm{BPH}$-egg and BPH-egg-infected rice stem tissues but was absent in uninfected rice stem tissues. Asaia may transfer from female BPHs to rice, likely mediated by an egg-smearing mechanism while BPHs are laying eggs inside the rice stem. The strong adhesive and antibacterial properties of Asaia may influence the attachment and survival of the eggs on rice. Taking this observation further, we speculate that Asaia may also play a role in the fitness of the $\mathrm{BPH}$ and that its cross-colonization property may support its use as a paratransgenic tool for the control of BPH in the infestation of rice. However, this requires further study.

\section{Conclusions}

This study demonstrated that members of Proteobacteria were predominant in all $\mathrm{BPH}$ samples. The $\mathrm{BPH}-$ associated bacterial diversity may be due to the recruitment of various microbiomes from the extrinsic habitat. This diverse bacterial population can play an important 
role in $\mathrm{BPH}$-rice interactions and influence $\mathrm{BPH}$ survival in rice (susceptible and resistant) hosts. Furthermore, the thorough Asaia documentation thus confirmed and established its interaction with adult BPHs, BPH eggs and rice. Now, with the extensive bacterial population catalogue thus established, this study will facilitate future experiments including the interaction of bacterial species with the insect phenotype. Even more broadly, it is necessary to further investigate the bacterial effect on insect associations with the host and to use native bacteria as a paratransgenic tool for insect control.

\section{Methods}

Total RNA-sequence analysis for bacterial populations in different BPH samples

Laboratory strains of BPH were collected in September 2007 from Guangdong Academy of Agricultural Sciences (GAAS), Guangzhou, in Guangdong Province, China, and a colony has been reared continuously on susceptible and resistant rice varieties in our laboratory since then. Different generations (F0, F6, and F16) of adult female (each 15) BPH samples from susceptible (TN1) and resistant rice (IR36 carrying the bph2 resistance gene and $\mathrm{RH}$ carrying the Bph3 resistance gene) [58] varieties were used for the current study. Total RNA was isolated from adult BPH females using a total RNA extraction kit (Omega, Norcross, GA, USA) according to the manufacturer's instructions. Library construction and sequencing were performed by Vazyme Biotech Co., Ltd. (Nanjing, China) using the Illumina-HiSeq 2500 platform and PE100 as a sequencing strategy (data not shown in this manuscript). A total of $54.61 \mathrm{~GB}$ high quality reads (data not shown in this manuscript) were obtained from the BPH samples. An average of 7.8 G reads from seven different $\mathrm{BPH}$ samples named BPH-F0 (F0 generation), BPH-F6-TN1 (F6 generation $\mathrm{BPH}$ from TN1), BHP-F16-TN1 (F16 generation BPH from TN1), $\mathrm{BPH}-\mathrm{F6}$-IR36 (F6 generation $\mathrm{BPH}$ from IR36), $\mathrm{BPH}-$ F16-IR36 (F16 generation BPH from IR36), BPH-F6-RH (F6 generation BPH from $\mathrm{RH}$ ) and BPH-F16-RH (F16 generation $\mathrm{BPH}$ from $\mathrm{RH}$ ) were analysed to identify the microbial community structure across the samples using the $16 \mathrm{~S}$ ribosomal RNA Sequences database from National Center for Biotechnology Information (NCBI), USA (https://www.ncbi.nlm.nih.gov) (see Additional files $6,7,8,9,10,11$ and 12).

\section{Sample collection}

To study the dynamics of Asaia in the short- and longwinged (adults; male and female) BPHs, the BPH samples were randomly collected from the entire rice field in Shaoguan city in Guangdong Province, China and stored in $100 \%$ alcohol. The rest of the BPH samples used in this study were maintained in the greenhouse at State Key
Laboratory of Biocontrol, Sun Yat-sen University, Guangzhou in Guangdong Province, China under standard conditions [59]. The procedure described by Ojha et al. [19] was applied to grow different rice varieties. The BPHs (50 each of females and males) were released on 10-15-day-old plants, and on day 1 , the plastic trays with plants were transferred to a humidity (70-90\%) chamber for the process of egg incubation. The adult BPHs were collected from "Huang Huas Zhan" (HHZ, a Chinese susceptible rice variety) and IR36. Entomological needles were used to isolate intact eggs from "HHZ" rice within $48 \mathrm{~h}$ and preserved in alcohol (100\%). Nearly 200 intact eggs were collected and used for the entire experiment. Thirty short- and long-winged BPH adults were also collected from field rice, both susceptible and resistant rice varieties. To study the Asaia identification on the rice host, $300 \mathrm{mg}$ of BPH egg-infected and uninfected tissues of susceptible rice were collected.

\section{Isolation of DNA from the BPH and rice samples}

The collected $\mathrm{BPH}$ samples were frozen at $-20^{\circ} \mathrm{C}$ for 5 min, immersed in $5 \% \mathrm{NaOCl}$ (sodium hypochlorite), and rinsed with sterile distilled water five times to remove surface microorganisms. Total DNA was isolated from $\mathrm{BPH}$ adults and eggs using the Insect DNA kit (Omega Bio-tek, Inc., Norcross, GA, USA) according to the manufacturer's instructions. Total DNA from infected and uninfected rice tissues was extracted using the Plant DNA Kit (Omega Bio-tek, Inc., Norcross, GA, USA) according to the manufacturer's instructions. DNA concentrations were estimated using a NanoDrop 2000 spectrophotometer (Thermo Fisher Scientific, USA).

\section{Primer design and PCR amplification of Asaia from different $\mathrm{BPH}$ and rice samples}

The Asaia-specific primers were designed using the Asaia-specific 16S rRNA gene sequences belonging to the accession numbers:- NR_122089.1, NR_112880.1, NR_024810.1, NR_114144.1, NR_041564.1, NR_1138 49.1, NR_024728.1, NR_112879.1, NR_112953.1, NR_ 113845.1, and NR_024738.1 (see Additional file 13). PCR amplification of the $\sim 400$ bp 16S rRNA gene sequence of Asaia was performed using the Asaia primers (forward: 5'-GGCGCGTAGGCGGTTTACAC-3' and reverse: 5'-TGCGCGTTGCTTCGAATTAAACCA-3') to evaluate their presence in various samples of BPHs and rice. Actin-gene (NCBI-GenBank: EU179846.1) specificprimers (forward: 5' -TGCGTGACATCAAGGAGA-3' and reverse: $5^{\prime}$-TGTTCCAGCCTTCCTT-3') were used and PCR-amplified $\sim 174 \mathrm{bp}$ actin gene, a housekeeping gene used as an internal control for the normalization of PCR data. Ten ng DNA of short- and long-winged (adults), egg, egg-infected and uninfected rice tissues were used as the template for PCR, and the PCR volume 
was $25 \mu \mathrm{l}$. PCRs were performed with $200 \mu \mathrm{M}$ dNTPs (New England Biolabs Inc.), 0.5 U Q5 Hot start high-fidelity Taq DNA polymerase (New England Biolabs Inc.), and $13 \mu \mathrm{M}$ primers (each). The thermal cycler protocol was $98{ }^{\circ} \mathrm{C}$ for $5 \mathrm{~min}, 35 \mathrm{cycles}$ at $98^{\circ} \mathrm{C}$ for $30 \mathrm{~s}, 56^{\circ} \mathrm{C}$ for $45 \mathrm{~s}$, and $72^{\circ} \mathrm{C}$ for $30 \mathrm{~s}$, and a final 5 min extension at $72^{\circ} \mathrm{C}$. The PCR conditions for actin-gene amplification from each BPH sample were $94{ }^{\circ} \mathrm{C}$ for $5 \mathrm{~min}, 35$ cycles at $94{ }^{\circ} \mathrm{C}$ for $30 \mathrm{~s}, 54^{\circ} \mathrm{C}$ for $30 \mathrm{~s}$, and $72^{\circ} \mathrm{C}$ for $45 \mathrm{~s}$, and a final $5 \mathrm{~min}$ extension at $72{ }^{\circ} \mathrm{C}$. Amplicons were run on $1 \%(\mathrm{w} / \mathrm{v})$ agarose gel to analyse band size. The EtBrstained gels were viewed and photographed in our gel documentation system (GL212PRO Imager, Carestream Health Inc., USA), and captured-gel images were saved in JPEG format. Then, ImageJ software (https://imagej. nih.gov/ij/) was used to estimate the relative colour intensities of each amplicons.

\section{Statistical analysis}

The normal distribution and alpha diversity (Shannon and Simpson's diversity indices, Evenness, Fisher alpha, Brillouin, Fisher alpha, Berger-Parker and Chao1) index were used to evaluate the differences in bacterial populations between BPH samples (obtained from both susceptible and resistant rice varieties) used in the current study. PCoA plots were plotted using PAST (Palaeontological Statistics, version 3) software. To show the relative abundance of microbial phyla for the respective BPH samples, heat maps were created using Gene Cluster 3.0 and TreeView software.

\section{Additional files}

Additional file 1: Normal distribution test of bacterial population in the $\mathrm{BPH}$ samples. (DOCX $14 \mathrm{~kb}$ )

Additional file 2: Details of OTU ID and its NCBI-blast, $16 \mathrm{~S}$ rRNA database, and details of the closest-matched accession numbers for BPH-F0, BPH-F6TN1, BPH-F16-TN1, BPH-F6-IR36, BPH-F16-IR36, BPH-F6-RH, and BPH-F16-RH samples. (PDF $92 \mathrm{~kb}$ )

Additional file 3: Overview of the bacterial population across the $\mathrm{BPH}$ samples. (PDF $85 \mathrm{~kb}$ )

Additional file 4: Comparison of the bacterial populations across the $\mathrm{BPH}$ (F6 + F16 generation BPHs collected from susceptible, TN1, and resistant, IR36 and $\mathrm{RH}$, rice varieties) samples at the genera level. Reduction and increase in the bacterial population across the BPH (F6 + F16 generation BPHs collected from the susceptible, TN1, rice variety) samples when compared with the BPH (F6 + F16 generation $\mathrm{BPH}$ collected from resistant, IR36 and $\mathrm{RH}$, rice variety) samples at the genus level. (DOCX $17 \mathrm{~kb}$ )

Additional file 5: Identification of a unique bacterial population among the $\mathrm{BPH}$ samples. Total number of unique bacteria among the $\mathrm{BPH}$ samples (a), shared bacteria between the BPH samples (b), and (c) specific bacterial name among the BPH samples. (DOCX $16 \mathrm{~kb}$ )

Additional file 6: Bacterial sequences of the $\mathrm{FO}$ generation $\mathrm{BPH}$. (PDF $90 \mathrm{~kb}$ )

Additional file 7: Bacterial sequences of the $\mathrm{F} 6$ generation $\mathrm{BPH}$ s from the susceptible, TN1, rice variety. (PDF $84 \mathrm{~kb}$ )
Additional file 8: Bacterial sequences of the $\mathrm{F} 16$ generation $\mathrm{BPH}$ from the TN1 rice variety. (PDF $86 \mathrm{~kb}$ )

Additional file 9: Bacterial sequences of the F6 generation BPHs from the resistant, IR36, rice variety. (TXT $22 \mathrm{~kb}$ )

Additional file 10: Bacterial sequences of the F16 generation BPHs from the IR36 rice variety. (XLSX $18 \mathrm{~kb}$ )

Additional file 11: Bacterial sequences of the $\mathrm{F} 6$ generation $\mathrm{BPH}$ from the resistant, $\mathrm{RH}$, rice variety. (XLSX $10 \mathrm{~kb}$ )

Additional file 12: Bacterial sequences of the $\mathrm{F} 16$ generation $\mathrm{BPH}$ from the $\mathrm{RH}$ rice variety. (PDF $87 \mathrm{~kb}$ )

Additional file 13: Asaia-specific primer design. Asaia-specific 16S rRNA gene sequences belonging to the NCBI Accession Numbers NR_122089.1, NR_112880.1, NR_024810.1, NR_114144.1, NR_041564.1, NR_113849.1, NR_024728.1, NR_112879.1, NR_112953.1, NR_113845.1, and NR_024738.1 were used. (PDF $85 \mathrm{~kb}$ )

\section{Abbreviations}

OTUs: operational taxonomic units; PCR: polymerase chain reaction; RH: Rathu Heenati; TN1: Taichung Native1

\section{Acknowledgements}

We thank Longgyu Yuan for their assistance with insect maintaining in green house at State Key Laboratory of Biocontrol, SunYat-sen University, China. The Authors thank Dr. Ruchi Agrawal, International Centre for Genetic Engineering and Biotechnology (ICGEB), New Delhi, for critical review of the manuscript.

\section{Authors' contributions}

WZ and $\mathrm{AO}$ conceived and designed the experiments. AO performed the experiments and analyzed the data. AO and WZ wrote the manuscript. Both authors have read and approved the final manuscript.

\section{Funding}

This work was funded by the National Natural Science Foundation of China (U1401212) to WZ. AO thanks State Key Laboratory of Biocontrol visiting scholar foundation for a research grant (SKLBC15F02), SunYat-sen University, China. The funders had no role in study design, data collection and analysis, preparation of the manuscript, or decision to publish.

\section{Availability of data and materials}

All data is given in the main body of the manuscript; materials are available from the authors. All sequence data is added to manuscript as additional files (named as Additional files 2, 3, 4, 5, 6, 7, 8, 9, 10, 11 and 12).

\section{Ethics approval and consent to participate}

Insect samples were either maintained at our greenhouse at State Key Laboraton of Biocontrol, Sun Yat-sen University or obtained from the entire rice field in the Shaoguan city in Guangdong Province, China - no permission required.

\section{Consent for publication}

Not applicable.

\section{Competing interests}

The authors declare that they have no competing interests.

\section{Author details}

${ }^{1}$ State Key Laboratory of Biocontrol and School of Life Sciences, Sun Yat-sen University, Guangzhou 510275, Guangdong, China. ${ }^{2}$ State Key Laboratory of Tea Plant Biology and Utilization, Anhui Agricultural University, Hefei 230036, Anhui, China.

Received: 17 January 2019 Accepted: 10 June 2019

Published online: 24 June 2019

\section{References}

1. Douglas AE. Nutritional interactions in insect-microbial symbiosis: aphids and their symbiotic bacteria Buchnera. Annu Rev Entomol. 1998;43:17-37.

2. Baumann P. Biology of bacteriocyte-associated endosymbionts of plant sapsucking insects. Annu Rev Entomol. 2005;59:155-89. 
3. Hurst GD, Jiggins FM. Male-killing bacteria in insects: mechanisms, incidence, and implications. Emerg Infect Dis. 2000;6(4):329-36.

4. Stouthamer R, Breeuwer JA, Hurst GD. Wolbachia pipientis: microbial manipulator of arthropod reproduction. Annu Rev Entomol. 1999:53:71-102.

5. Heath BD, Butcher RD, Whitfield WG, Hubbard SF. Horizontal transfer of Wolbachia between phylogenetically distant insect species by a naturally occurring mechanism. Curr Biol. 1999;9:313-6.

6. Siozios S, Sapountzis $P$, loannidis $P$, Bourtzis K. Wolbachia symbiosis and insect immune response. Insect Science. 2008;15:89-100.

7. Brown planthopper: threat to rice production in Asia. International Rice Research Institute, Los Banos, Laguna, Philippines, The brown planthopper 1979;p.3-17.

8. Cheng JA, Holt J. A systems analysis approach to brown planthopper control on rice in Zhejinag Province, China 1 simulation of outbreaks. J Appl Ecol. 1990;271:85-99.

9. Sun ZX, Zhai YF, Zhang JQ, Kang K, Cai JH, Fu Y, et al. The genetic basis of population fecundity prediction across multiple field populations of Nilaparvata lugens. Mol Ecol. 2015;24(4):771-84.

10. Noda H, Kawai S, Koizumi Y, Matsui K, Zhang Q, Furukawa S, et al. Annotated ESTs from various tissues of the brown planthopper Nilaparvata lugens: a genomic resource for studying agricultural pests. BMC Genomics. 2008;9:117.

11. Horgan F. Mechanisms of resistance: a major gap in understanding planthopper-rice interactions. Planthoppers: new threats to the sustainability of intensive rice production systems in Asia. Edited by Heong KL, Hardy B. Los Baños (Philippines): International Rice Research Institute 2009;281-302.

12. Sōgawa K. The rice brown planthopper: feeding physiology and host plant interactions. Annu Rev Entomol. 1982;27:49-73.

13. Cook AG, Denno RF. Planthopper/plant interactions: feeding behavior, plant nutrition, plant defense, and host plant specialization. In: Denno RF, Pefect TJ, editors. Planthoppers. Boston, MA: Springer; 1994. p. 114-39.

14. Chen CC, Cheng LL, Hou RF. Studies on the intracellular yeast like symbiote in the brown planthopper, Nilaparvata lugens Stal. II. Effects of antibiotics and elevated temperature on the symbiotes and their host. J Appl Entomol. 1981:92:440-9.

15. Sasaki T, Kawamura M, Ishikawa $H$. Nitrogen recycling in the brown planthopper, Nilaparvata lugens: involvement of yeast-like endosymbionts in uric acid metabolism. J Insect Physiol. 1996;42:125-9.

16. Lu ZX, Yu XP, Chen JM, Zheng XS, Xu HX, Zhang JF, Chen LZ. Dynamics of yeats-like symbiote and its relationship with the virulence of brown planthopper, Nilaparvata lugens Stal, to resistant rice varieties. J Asia Pac Entomol. 2004;7(3):317-23.

17. Chen YH, Bernal CC, Tan J, Horgan FJ, Fitzgerald MA. Planthopper 'adaptation' to resistant rice varieties: changes in amino acid composition over time. J Insect Physiol. 2011;57:1375-84.

18. Qiang F, Zhang Z, Cui H, Lai F, Sun Z. A chemically defined diet enables continuous rearing of the brown planthopper, Nilaparvata lugens (Stal) (Homoptera: Delphacidae). Appl Entomol Zool. 2001;36(1):111-6.

19. Ojha A, Sinha DK, Padmakumari AP, Bentur JS, Nair S. Bacterial community structure in the Asian rice gall midge reveals a varied microbiome rich in Proteobacteria. Sci Rep. 2017;7(1):9424.

20. Karakus M, Karabey B, Orçun Kalkan \$̧, Özdemir G, Oğuz G, Erişöz Kasap Ö et al. Midgut bacterial diversity of wild populations of Phlebotomus (P.) papatasi, the vector of zoonotic cutaneous Leishmaniasis (ZCL) in Turkey. Sci Rep. 2017;7(1):14812.

21. Krams IA, Kecko S, Jõers P, Trakimas G, Elferts D, Krams R, et al. Microbiome symbionts and diet diversity incur costs on the immune system of insect larvae. J Exp Biol. 2017;220:4204-12.

22. Yun JH, Roh SW, Whon TW, Jung MJ, Kim MS, Park DS, et al. Insect gut bacterial diversity determined by environmental habitat, diet, developmental stage, and phylogeny of host. Appl Environ Microbiol. 2014;80:5254-64.

23. Douglas AE. Multiorganismal insects: diversity and function of resident microorganisms. Annu Rev Entomol. 2015;60:17-34.

24. Galand PE, Casamayor EO, Kirchman DL, Lovejoy C. Ecology of the rare microbial biosphere of the Arctic Ocean. Proc Natl Acad Sci U S A. 2009;106: 22427-32.

25. Rampelotto $\mathrm{PH}$, de Siqueira Ferreira $A$, Barboza AD, Roesch LF. Changes in diversity, abundance, and structure of soil bacterial communities in Brazilian savanna under different land use systems. Microb Ecol. 2013;66:593-607.

26. Roesch LF, Fulthorpe RR, Riva A, Casella G, Hadwin AK, Kent AD, et al. Pyrosequencing enumerates and contrasts soil microbial diversity. ISME J. 2007;1:283-90.
27. Broderick NA, Lemaitre B. Gut-associated microbes of Drosophilla melanogaster. Gut Microbes. 2012;3:307-21.

28. Meriweather M, Mathews S, Rio R, Baucom RS. A 454 survey reveals the community composition and core microbiome of the common bed bug (Cimex lectularius) across an urban landscape. PLoS One. 2013;8(4):e61465.

29. Zouache K, Raharimalala FN, Raquin V, Tran-Van V, Raveloson LH, Ravelonandro P, Mavingui P. Bacterial diversity of field-caught mosquitoes, Aedes albopictus and Aedes aegypti, from different geographic regions of Madagascar. FEMS Microbiol Ecol. 2011;75:377-89.

30. Narasimhan S, Fikrig E. Tick microbiome: the force within. Trends Parasitol. 2015;31:315-23.

31. Wei Z, Hu W, Lin Q, Cheng X, Tong M, Zhu L, et al. Understanding rice plant resistance to the brown planthopper (Nilaparvata lugens): a proteomic approach. Proteomics. 2009;9(10):2798-808.

32. Alagar M, Suresh S, Samiyappan R, Saravanakumar D. Reaction of resistant and susceptible rice genotypes against brown planthopper (Nilaparvata lugens). Phytoparasitica. 2007:35:346.

33. Blaser MJ, Webb GF. Host demise as a beneficial function of indigenous microbiota in human hosts. mBio. 2014;5(6):e02262-14.

34. Doughari HJ, Ndakidemi PA, Human IS, Benade S. The ecology, biology and pathogenesis of Acinetobacter spp.: an overview. Microbes Environ. 2011; 26(2):101-12.

35. Valero-Guillen PL, Yague G, Segovia M. Characterization of acylphosphatidylinositol from the opportunistic pathogen Corynebacterium amycolatum. Chem Phys Lipids. 2005;133(1):17-26.

36. Alauzet C, Teyssier C, Jumas-Bilak K, Gouby A, Chiron R, Rabaud C, et al. Gluconobacter as well as Asaia species, newly emerging opportunistic human pathogens among acetic acid bacteria. J Clin Microbiol. 2010;48(11):3935-42.

37. Eberhard WG. Evolution in bacterial plasmids and levels of selection. Q Rev Biol. 1990;65(1):3-22.

38. Palmen R, Vosman B, Buijsman P, Breek CK, Hellingwerf KJ. Physiological characterization of natural transformation in Acinetobacter calcoaceticus. J Gen Microbiol. 1993;139(2):295-305.

39. Winstanley C, Taylor SC, Williams PA. pWW174: a large plasmid from Acinetobacter calcoaceticus encoding benzene catabolism by the betaketoadipate pathway. Mol Microbiol. 1987;1(2):219-27.

40. Schembri MA, Bayly RC, Davies JK. Cloning and analysis of the polyhydroxyalkanoic acid synthase gene from an Acinetobacter sp: evidence that the gene is both plasmid and chromosomally located. FEMS Microbiol Lett. 1994;118:145-52.

41. Vaneechoutte M, Nemec A, Musilek M, van der Reijden TJ, van der Barselaar $M$, Tjernberg I, et al. Description of Acinetobacter venetianus ex Di cello et al. 1997 sp. nov. Int J Syst Evol Microbiol. 2009;59:1376-81.

42. Engel P, Moran NA. The gut microbiota of insects-diversity in structure and function. FEMS Microbiol Rev. 2013;37(5):699-735.

43. Visôtto LE, Oliveira MG, Guedes RN, Ribon AO, Good-God PI. Contribution of gut bacteria to digestion and development of the velvetbean caterpillar, Anticarsia gemmatalis. J Insect Physiol. 2009;55(3):185-91.

44. Feng $W$, Wang XQ, Zhou W, Liu GY, Wan YJ. Isolation and characterization of lipase-producing bacteria in the intestine of the silkworm, Bombyx mori, reared on different forage. J Insect Sci. 2011;11(135).

45. Khurana S, Sanli G, Powers DB, Anderson S, Blaber M. Molecular modeling of substrate binding in wild-type and mutant Corynebacteria 2,5-diketo-Dgluconate reductases. Proteins. 2000;39(1):68-75.

46. Tang $M, L v L$, Jing $S$, Zhu L, He G. Bacterial symbionts of the brown planthopper, Nilaparvata lugens (Homoptera: Delphacidae). Appl Environ Microbiol. 2010;76(6):1740-5.

47. Gonella E, Crotti E, Rizzi A, Mandrioli M, Favia G, Daffonchio D, Alma A. Horizontal transmission of the symbiotic bacterium Asaia sp. in the leafhopper Scaphoideus titanus ball (Hemiptera: Cicadellidae). BMC Microbiol. 2012;12(Suppl 1):S4.

48. Robinson CJ, Schloss P, Ramos Y, Raffa K, Handelsman J. Robustness of the bacterial community in the cabbage white butterfly larval midgut. Microb Ecol. 2010;59(2):199-211.

49. Capone A, Ricci I, Damiani C, Mosca M, Rossi P, Scuppa P, et al. Interactions between Asaia, Plasmodium and Anopheles: new insights into mosquito symbiosis and implications in malaria symbiotic control. Parasit Vectors. 2013;6(1):182.

50. Kruk T, Szczepanowicz K, Kregiel D, Szyk-Warszynska L, Warszynski P. Nanostructured multilayer polyelectrolyte films with silver nanoparticles as antibacterial coatings. Colloids SurfB Biointerfaces. 2015;137:158-66. 
51. Mitraka E, Stathopoulos S, Siden-Kiamos I, Christophides GK, Louis C. Asaia accelerates larval development of Anopheles gambiae. Pathog Glob Health. 2013;107(6):305-11.

52. Chouaia B, Rossi P, Epis S, Mosca M, Ricci I, Damiani C, et al. Delayed larval development in Anopheles mosquitoes deprived of Asaia bacterial symbionts. BMC Microbiol. 2012;12(Suppl1):S2.

53. Damiani C, Ricci I, Crotti E, Rossi P, Rizzi A, Scuppa P, et al. Mosquitobacteria symbiosis: the case of Anopheles gambiae and Asaia. Microb Ecol. 2010;60(3):644-54.

54. Crotti E, Damiani C, Pajoro M, Gonella E, Rizzi A, Ricci I, et al. Asaia, a versatile acetic acid bacterial symbiont, capable of cross-colonizing insects of phylogenetically distant genera and orders. Environ Microbiol. 2009; 11(12):3252-64.

55. Epis S, Gaibani P, Ulissi U, Chouaia B, Ricci I, Damiani C, et al. Do mosquitoassociated bacteria of the genus Asaia circulate in humans? Eur J Clin Microbiol Infect Dis. 2012;31(6):1137-40.

56. Bongio NJ, Lampe DJ. Inhibition of Plasmodium berghei development in mosquitoes by effector proteins secreted from Asaia sp. bacteria using a novel native secretion signal. PLoS One. 2015;10(12):e0143541.

57. Samaddar N, Paul A, Chakravorty S, Chakraborty W, Mukherjee J, Chowdhuri D, Gachhui R. Nitrogen fixation in Asaia sp. (family Acetobacteraceae). Curr Microbio. 2011:63:226-31.

58. Jena KK, Kim SM. Current status of brown planthopper (BPH) resistance and genetics. Rice. 2010;3:161-71.

59. Pang R, Qiu J, Li T, Yang P, Yue L, Pan Y, Zhang $W$. The regulation of lipid metabolism by a hypothetical P-loop NTPase and its impact on fecundity of the brown planthopper. Biochim Biophys Acta Gen Subj. 2017;1861(7):1750-8.

\section{Publisher's Note}

Springer Nature remains neutral with regard to jurisdictional claims in published maps and institutional affiliations.

Ready to submit your research? Choose BMC and benefit from:

- fast, convenient online submission

- thorough peer review by experienced researchers in your field

- rapid publication on acceptance

- support for research data, including large and complex data types

- gold Open Access which fosters wider collaboration and increased citations

- maximum visibility for your research: over $100 \mathrm{M}$ website views per year

At $\mathrm{BMC}$, research is always in progress.

Learn more biomedcentral.com/submissions 